\title{
Reflections on Student Support in Open and Distance Learning
}

\author{
Alan Tait, Guest Editor \\ Faculty of Education and Language Studies \\ Open University UK
}

This is a very interesting moment to reflect on Student Support in Open and Distance Learning (ODL). After some 10 years of the radical intrusion of a range of technologies, principally those grouped around what has been broadly termed ICT, we have the chance to see if and how the world of ODL has qualitatively changed. I suggest that those of us who began our careers more than a decade ago are like those survivors in a landscape painting of a battle, peering about the field while some wisps of smoke still hang in the air from earlier cannon barrage. But the battle that the picture represents is over. There are new authorities in place, and of course there are losers: those who have lost power if not their lives. We look to see who has died, which amongst the wounded can be given help, while those who walk away wonder if the world has really changed. Have we just substituted one set of powerful rulers for another? Or has the way we live our lives been altered forever?

To begin with a historical perspective on the European context, as is well known correspondence education is said to have begun in England in 1844 with Isaac Pitman's shorthand course delivered by correspondence, using the new postal system, enabled in its turn by the rail system that was beginning to make travel and communication across England quicker than ever before (Shrestha, 1997). The crucial dimension of Pitman's system was that he corrected students' work and sent it back to them. Thus although separated from the teacher, students received feedback, together we can at least imagine with encouragement from their tutor. Parallel developments were taking place in Germany at a similar period, facilitated also by postal systems and the railway. Thus a crucial aspect was initiated of what was to remain constant through changes of technology and terminology from correspondence to distance education, to open and distance learning, and on to flexible, Web-based and e-learning. This was the provision of an integrated system which provided learning materials or direct teaching to students and gave them feedback in a timely way on the work they undertook, thus helping the learner and the institution to assess their understanding.

The next crucial step in historical development was the opening up by the University of London in 1858 of a range of programmes for external study: that is to say that students could follow the University of London curriculum for a range of degrees and sit the examinations without ever setting foot in London. This was extraordinary: it meant that the link between study and place was broken, a link that continues for older fashioned universities such as the University of Cambridge to this day, where undergraduates have to live within a certain number of miles of the University Church in order to be deemed to be 'at' the university at all. The University of London 
Tait, Vol. 4, No. 1 Editorial: Reflections on Student Support in Open and Distance Learning

has been termed the first 'Open University' because of this move (Bell and Tight, 1993), and students all round the world, but principally within the British Empire and its dominions, were soon looking for tutorial support to supplement the bare syllabus they received on registration wherever they lived. The history of the University Correspondence College and its founder William Briggs provides an insight into the pioneering work, which began in 1887 in providing support to those studying with the University of London at a distance. Briggs' college provided a correspondence tuition scheme by post, along with face to face day and evening teaching in London and Cambridge, short residential schools, and the production and sale of specially written texts to help students (De Salvo, 2002). Briggs thus prefigured the range of services taken up in modern distance education from say 1870-1995, and his system was very effective. It provided, first of all, support for a crucial opening for women to study for degrees wherever they lived, at a time when they were still excluded from the ancient universities in England. At a more general level, between 1887 and 1931, 39,326 external students are recorded as passing University of London examinations, with some 10,000 gaining Bachelors or even Masters Degrees (De Salvo, 2002, p. 39). While the number of London External students in the UK has decreased due to the wider availability of opportunity to study, support for such students is still mounted from a small number of colleges.

The story now moves on to 1946 in South Africa and the establishment of the world's first exclusively distance teaching university, the University of South Africa (UNISA). UNISA, based in the country's capital Pretoria, recruited large numbers of students, and remarkably during the apartheid period remained a university not classified by the ethnic or racial group it was allowed to teach, as were almost all other Higher Education institutions. UNISA, however, offered opportunity to large numbers of black and so-called coloured students significantly excluded from educational opportunity as well as political rights, along with whites who were in a minority in the country. However, major weaknesses in the UNISA system identified after apartheid was ended included very importantly:

- Low success in terms of completion and throughput rates

- The correspondence nature of programmes in comparison with well-functioning distance education

- Inadequate learner support which is exacerbated by the lack of a co-ordinated regional network of learning centres

(SAIDE as cited in Nonyongo, 2002, p.128)

While it is very difficult to isolate the variables in an educational system and identify a simple causal relationship of learner support with student success, the UNISA example before reform provides the clearest case for the importance of learner support in a distance education institution. For many students, especially from the majority population who were excluded from the best universities in South Africa, the opportunity offered by distance education was not a real one. UNISA provides us with the best-documented case hitherto of the dangers of developing distance education without adequate learner support.

It was not until the establishment of the Open University UK in 1969 that modern distance education was formed by the development of a range of learning and teaching media along with an integrated student support system. The University succeeded in a radically different task from that which had been asked of Higher Education in the UK up till that time. It was asked to recruit post-experience adult students who had not hitherto considered Higher Education, as opposed to the usual intake for universities of a small well-qualified cohort of school leavers. In other words, 
Tait, Vol. 4, No. 1 Editorial: Reflections on Student Support in Open and Distance Learning

the OU UK was asked to change the educational expectations of sectors of the population who had been excluded by the very limited opportunities for university education up to that time. It was also asked to do this at scale, in other words to make a radical intervention in terms of the numbers as well as the kinds of people. Lastly it was to do something which remains unique, to offer places for undergraduate study without barrier of former qualification. That is to say students chose the university and not the other way around. There were a number of key elements in the OU system which drew on the work of the correspondence colleges for the University of London External Student scheme, and were influenced by the thinking of Michael Young and the then fledgling institution he created out of their wake, the National Extension College. The characteristics of the learner support system for the OU UK included:

- Each student had a personal tutor, in a group with no more than 25 or so other students in order to allow personal knowledge, support and understanding to grow up through the lifetime of a course

- The tutor gave teaching feedback and the mark for work completed during the course, thus having a pivotal role in supporting student learning and progress (and which gave rise to the serious development of the teaching skill known now as correspondence teaching)

- All students were offered the opportunity but not the obligation to take part in face to face tutorials, and more recently computer-mediated tutorials, managed by their own tutor (online courses still only remain a tiny minority within the overall provision of the OU UK)

- A network of some 260 study centres were established throughout the UK in order to provide such tutorial opportunities, supported by 13 Regional Centres, thus ensuring that the student felt 'nearer' the university whose headquarters are in central England

- A limited amount of residential school experience on a conventional campus was essential, at a minimum one week

- $\quad$ From 1971 -1997 all undergraduate students - i.e., the great majority, had access to a personal tutor-counsellor who offered them support and advice throughout their career with the university whatever course they were on, providing for what was called 'continuity of counselling' (Tait, 1998).

While there has been substantial revision of the OU UK system since the original blueprint, the core role of the tutor who works with a group of students of no more than 25 in number, and who teaches and grades their work, continues to be seen as at the heart of learner support.

What then are the main reasons for having student support integrated in an ODL system?

\section{Students want Support}

The first of these is that students want it. While this might be said to be pedagogically weak in the theoretical sense, it is important for the best of reasons. The first is that students are more and more in a position of being able to choose with whom they study: thus competition makes it imperative that institutions can offer what students say they want. While students look for the 
Tait, Vol. 4, No. 1 Editorial: Reflections on Student Support in Open and Distance Learning

flexibility that ODL offers, especially freedom from time and place that is restricted by conventional part-time study, this is not the same for the great majority as saying that they do not want support. In the OU UK student feedback tells us that some 10 per cent of students do not want interaction with other students, having perhaps a personality type that has led them to choose a study mode that reduces or removes the need for interaction with others. However, for the other 90 per cent, this is looked for, albeit not always taken up because of the demands on time and place that are so prevalent in the lives of adult learners.

\section{The Reduction of Drop-out}

Student support, especially student guidance and counselling, tutor support, and effective information and administrative systems all provide a range of activity that impacts not only in terms of teaching but also affectively, that is to say reinforcing the student sense of confidence, self-esteem and progress. Further, intervention when students have not contributed work on time can make a timely and effective contribution to the reduction of drop-out. The extent to which student support creates a learning environment that is congenial, attractive and therefore supportive of learner persistence is always difficult to estimate, but the wider affective dimensions of the learning environment which revolve around what I have elsewhere termed 'conversation and community' seem to be important in most educational contexts and there is therefore no reason to assume that for most learners they will not be important in ODL, even though delivering them is more difficult (Tait, 1996). This mode of explanation can be seen as related to that developed in terms of the community of practice in ODL that contains learners and their teachers, especially within Web-supported learning environments (Thorpe, 2002).

\section{The Nature of Learning}

A further mode of explanation for student support, especially for tutoring in group work in study centres or online and in the teaching given through the return of assignments, lies in the impact this makes on the learning process. Essentially this has been termed 'mediation,' that is the role that the tutor performs in relating the teaching content to the student as an individual in her or his situation, including the social, economic, geographic and cultural dimensions. In other words, the tutor in coming alongside the student and the teaching material adds a voice that helps the student to relate concepts, values, and lines of enquiry to the particular situation. Over the last ten or so years this has come increasingly to be related to constructivist modes of explanation about the creation of knowledge by the learner, and supported by the wider possibility for exploratory learning and teaching methods through the use of the Web which has expanded the potential for learning outside or independently of teaching materials provided. Earlier influential theoretical frameworks included that of 'didactic conversation' developed by Holmberg, and Moore's 'transactional distance' and 'instructional dialogue,' both of which elaborated the ways in which learning took place in contexts where distance between the teacher and the learner was significant (see Tait, 1996, pp. 61-63). Thorpe has more recently argued that Web-based learning has the potential to elide the conceptual distinction between learning materials and learner support which has governed this field: this surely is an issue of theory that need further development and represents the best articulated account yet of change of a radical nature in student support in ODL with the advent of ICT (Thorpe, 2002).

Drawing on this range of explanatory work we can summarise the rationale for student support as being:

- $\quad$ Cognitive (supporting and developing learning) 
Tait, Vol. 4, No. 1 Editorial: Reflections on Student Support in Open and Distance Learning

- Affective (that is related to the emotions that support learning and success)

- Systemic (helping students to manage rules and systems of the institution in ways that that support persistence)

Tait (2000. p. 289)

This schematic explanation separates out for heuristic purposes what is usually and at its best integrated and mutually reinforcing. Student support in ODL has as its primary aim that of assisting students to learn successfully, and in doing so it recognises that in learning and teaching systems characterised by distance and part-time study helping students with their feelings of confidence and self-esteem will energise them in ways that support persistence and success. At the same time what are often institutional or social barriers can be addressed in problem solving and facilitative ways, reinforcing learning and the affective dimension. Innovation with ICTbased systems can deliver these goals very effectively.

But is any of this, in essence, changed by the revolution in media we have undergone over the last decade? I suggest yes and no, an answer representing perhaps no more in some readers' minds than the incapacity of the English to state their minds (our particular contribution to world culture!). But, in fact, I hope a nuanced and helpful answer can be developed by those reading the articles in this issue of IRRODL themselves. It seems to me to be the core task for those working and researching in the field of student support in ODL at this juncture. It is certainly time to move away from the exuberant and exaggerated claims of the pioneers of e-learning, whose work appears to assume that effective teaching and learning has not ever taken place until their own Web supported programme was created, or that large scale opportunity for adult learners was never conceived until the year 2000. There is enough evidence to show that along with success it is possible to waste as much money and time with Web-supported learning as it was with any other kind of educational programme. There are as many empty student e-conferences as there were empty study centres in second generation distance learning. Most importantly there are as many disappointed and dispirited learners who have dropped out of e-learning programmes as there were in second generation distance education. And yet, this is not the same as saying nothing has changed.

My own approach firstly would be to return to Moore's theory of transactional distance, and use that to evaluate what is happening in terms of learning and teaching in any e-learning programme (Moore 1993). The question of distance is of course now a fascinating one. While distance education was conceived at least in part to manage geographical distance - to mitigate its tyranny - in the empire that once was Canada and Australia, it was also the case through the 1970s and 1980s that distance education had globally more students in cities than in the countryside. We begin to understand that distance was a social as much if not more than a geographical phenomenon. However, the notion of place is more fundamentally challenged by e-learning than ever before. Commentators such as Giddens (1991) have explored how the ways in which we exist in our physical world are being reshaped by ICT. The question 'Does place matter?' has become much more complex to answer even than from the period of second generation distance education. Asynchronicity has done the same to time, although some of the rhetoric around it has masked the reality of time needed for study.

Thus the core notion of distance in Moore's theory - that the space between the learner and the structure of teaching must be mediated by dialogue, offering the learner the opportunity to be an active participant - remains valid, but needs to be challenged as all theory does by the application of new cases. The activities in e-conferencing and the new challenges for learners in searching 
Tait, Vol. 4, No. 1 Editorial: Reflections on Student Support in Open and Distance Learning

and evaluating materials in the Web seem to me to be developments from where we were, not radically new activities in themselves. However the ways in which e-learning re-conceives these as even more core to teaching and learning strategy than in second generation distance education does represent to me the opportunity to organise teaching and learning in qualitatively improved albeit not qualitatively different ways: greater ease of access at least for those in the world with technological infrastructures and money to support them; greater opportunities for student-student and student-tutor interaction; and greater opportunities to move away from the behavouristically influenced conceptions of a course and more towards the constructivism that is ever more influential. In terms of learning skills, the term 'connectivity' might cover not only the technical access, but the development of the broader range of literacies that are necessary to function effectively within the communities of e-learners, in order not to become a member of what is surely a new category of marginalised people that open and distance learning in this recent period of e-enthusiasm has at times been in peril of both creating and forgetting.

The fact that Moore's theory remains, in my view, the crucial framework of ideas against which such assertions as represented here can be tested gives weight to my initial thesis that there is a deal of continuity in e-learning from second generation distance education that is not acknowledged: perhaps inevitable when a radical interruption by a technology occurs. Now, however, is the time to stand back and reflect on what has changed and what in terms of learning theory remains broadly speaking the same.

Secondly I offer a summary of the account by Roger Mills and myself of the major change issues for learner support in ODL at present. Our proposed change issues included:

- The impact of ICT on what is wanted by learners today, what can be provided by institutions, and what restructuring of organisations has to follow

- The change of status from student to that of customer

- The pressure of educational policy to recruit participants from wider and wider social segments of society, in particular from those which have not traditionally taken part in education

- The pressures on costs for institutions in competitive environments

- The need to work in more complex ways with work related programmes that make the workplace a site of learning, and demand assessment methods of greater complexity

$$
\text { Tait and Mills (2002, pp.1-2) }
$$

This more pragmatic account of change describes a complex environment, and one where the temptation to 'do the easy things' in terms of curriculum and recruitment areas becomes too great for some institutions to refuse. The challenges do not drive conveniently towards obvious policy and organisational solutions, but indeed work in tension with each other. The key managerial achievement is to conclude the optimum resolution between them in a given situation.

I now go on to give readers a taste of what this issue on student support in ODL offers them. In my view it offers an important collection of articles in their own right as well as a very valuable set of resources to do just what I suggest is the core task at present in this field: does ICT change in essence how learners are supported in ODL, and if so how? 
Tait, Vol. 4, No. 1 Editorial: Reflections on Student Support in Open and Distance Learning

The contribution from Bernath and colleagues at the University of Oldenburg provides just such an evaluation in its account of how a study centre that was established nearly 30 years ago to be 'near' students has reconceived itself in an electronic age. While in some ways specific to the German context and the ways in particular that Higher Education is organised in that country, the article more importantly demonstrates how energetic and creative professionals can think their way through a technological revolution, ensuring that they enhance their service to learners rather than disappearing as the solution to yesterday's problem. Dearnley in her analysis of the ways in which students need support in the Nursing Programme at the University of Bradford, UK, grounds her work in a persuasive analysis of what students need. The analysis is of students and their learning: it starts where those of us working in this field need to base our reflection, rather than in the technology. However, Dearnley offers us this insightful comment in conclusion "as open and distance e-learning expands to permeate into the realm of e-learning, the findings of this study suggest that a major challenge will be to develop electronic forms of 'connected knowing groups' in order to support students and sustain their motivation for learning and development". We can see here too how there is continuity in the analysis of learner support rather than a radical divide between second and third generation ODL. This is also borne out in the work of LudwigHardman and Dunlap at Western Governors University, USA, where the authors describe their efforts in providing learner support to diminish attrition through the use of 'scaffolding,' borrowing from the now familiar vocabulary of Vygotsky, but also drawing on long established thinkers in the field of adult learning like Knowles. The fact that this takes place in an online environment represents the context, not the centre piece of the analysis. Bird and Morgan too from Southern Cross University, Australia, analyse the barriers to study for adult learners: they demonstrate the complex mix of affective and organisational issues that adult learners have to manage in making choices about study, and also the difficulty of their acting effectively as customers in choosing programmes and modes such as part-time, distance, on or off-campus, when they have initially so little to guide them. Finally in the Main Section, Fahy of Athabasca University, Canada, uses analysis of online student behaviour to deliver a most interesting and persuasive analysis of what students are doing when they relate to each other online. He finds that students learn to model the sorts of support they need in online asynchronous mode, and citing Moore writes "there is no simple association between distance and the perception of separation or isolation. Indeed face to face interaction may also suffer from various 'distances' (psychological, interpersonal, cultural, linguistic, environmental etc.), while anyone who has ever had a pen pal, or been caught up in an on-line relationship, knows the power of 'mere' asynchronous text to create and sustain interpersonal engagement.” Readers both of Les Liaisons Dangereuses and successful online conferences will bear witness to that!

The section for shorter pieces entitled 'Research Notes' bears out a similar story: that of continuity after the shock of rapid technological change. From Brazil's University of Santa Catarina, de Moraes and her colleagues give an account of how they have come to reflect on the need for student support in an online environment. From the University of Sydney, Australia, Morgan and McKenzie refers to transactional distance in their analysis of how the humanity of human beings must be recognised and supported in technologically sophisticated environments, and means by this the tutor on whom heavy demands are made as well as the student. And finally from India's Indira Gandhi Open University Chandar and Sharma provide a glimpse of how radio contributes to the lives of their students, a technology that has been in use for over 30 years in distance education.

All in all this is a fascinating issue to have worked on and I thank the Editorial Team at IRRODL for the opportunity to reflect myself through this Editorial on where we are in the field of student support in open and distance learning, as well as to have the privilege to stand at the head of an issue with such valuable contributions. The central place I have given to Moore's theory of 
transactional distance provides the opportunity to recognise the career of its originator, Prof Michael Moore, formerly of the OU UK, but for the most significant phase of his professional life at The Pennsylvania State University, USA. I would not want to miss this chance to recognise his contribution over so many years to our field, and to me personally as one of the most thoughtful, energetic and generous colleagues I have ever had the benefit of working with. I know the Editor of this journal, Dr. Peter Cookson, also shares these sentiments.

In conclusion, I believe the authors published here demonstrate that the clouds of smoke have more or less cleared after the violent revolution that has occurred with the impact of ICT into ODL over the last decade, and that the issues of learning, teaching and student support have reappeared as the heart of the matter. That is how it should be!

Alan Tait

Faculty of Education and Language Studies, Open University UK

a.w.tait@open.ac.uk

\section{References}

Bell, R., and Tight, M. (1993). Open Universities: A British Tradition? Society for Research into Higher Education, Buckingham: Open University Press.

De Salvo, A. (2002). The Rise and Fall of the University Correspondence College, pioneer of distance learning, Cambridge: National Extension College.

Giddens, A. (1991). Modernity and Self-Identity: Self and Society in the Late Modern Age, Cambridge: Polity Press.

Moore, M. (1993). Theory of Transactional Distance. In Keegan D (Ed.) Theoretical Principles of Distance Education (p 22-38). London: Routledge.

Nonyongo, E. P. (2002). Changing Entrenched Learner Support Systems. In A. Tait and R. Mills (Eds.), Rethinking Learner Support in Distance Education: Change and Continuity in an International Context (p.123-141). London: Routledge.

Tait, A. (1996). Conversation and Community: Student Support in Open and Distance Learning. In R Mills and A Tait (Eds.) Supporting the Learner in Open and Distance Learning (p. 59-72). London: Pitman.

Tait, A. (2000). Planning Student Support for Open and Distance Learning. Open Learning 15(3), $287-299$

Tait, A., and Mills, R. (2002). Introduction. In A. Tait and R. Mills (Eds.) Rethinking Learner Support in Distance Education: Change and Continuity in an International Context (p.12). London: Routledge.

Thorpe, M. (2002). Rethinking Learner Support: the Challenge of On-line Learning. Open Learning 17(2), $105-120$. 
Threstha, G. (1997), Distance Education in Developing Countries: Definition. United Nations Development Programme. Retrieved March 2003 from:

http://www.undp.org/info21/public/distance/pb-dis2.html

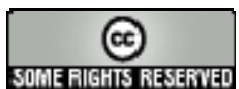

